\title{
Oral and Topical Antibiotics for Clinically Infected Eczema in Children: A Pragmatic Randomized Con- trolled Trial in Ambulatory Care
}

\author{
Nick A. Francis, $M D, P b D^{1}$ \\ Mattbew J. Ridd, $P b D^{2}$ \\ Emma Thomas-Jones, $P b D^{3}$ \\ Christopber C. Butler, FRCGP \\ Kerenza Hood, $\mathrm{PbD}^{3}$ \\ Victoria Shepherd, $M A^{3}$ \\ Charis A. Marwick, $P b D^{5}$ \\ Chao Huang, $P b D^{3}$ \\ Mirella Longo, $\mathrm{PbD}^{6}$ \\ Mandy Wootton, $\mathrm{PbD}^{7}$ \\ Frank Sullivan, FRSE ${ }^{8}$ \\ the CREAM Trial Management \\ Group \\ 'Division of Population Medicine, School of \\ Medicine, Cardiff University, Cardiff, Wales \\ ${ }^{2}$ School of Social and Community Medi- \\ cine, University of Bristol, Bristol, England \\ ${ }^{3}$ South East Wales Trials Unit, Centre for \\ Trials Research, Cardiff University, Cardiff, \\ Wales \\ ${ }^{4}$ Nuffield Department of Primary Care \\ Health Sciences, University of Oxford, \\ Oxford, England \\ ${ }^{5}$ Population Health Sciences, University of \\ Dundee, Dundee, Scotland \\ ${ }^{6}$ Swansea Centre for Health Economics, \\ Swansea University, Swansea, Wales \\ ${ }^{7}$ Specialist Antimicrobial Chemotherapy \\ Unit, Public Health Wales, University Hos- \\ pital Wales, Cardiff, Wales \\ ${ }^{8}$ Department of Family \& Community \\ Medicine and Dalla Lana School of Public \\ Health, North York General Hospital, Uni- \\ versity of Toronto, Toronto, Canada

\section{8 \\ MORE ONLINE \\ www.annfammed.org} \\ Conflicts of interest: authors report none.
}

\section{CORRESPONDING AUTHOR}

Nick A. Francis

Division of Population Medicine, School of Medicine, Cardiff University

Neuadd Meirionnydd, Heath Park, Cardiff, CF14 4YS

francisna@cf.ac.uk

\begin{abstract}
PURPOSE Eczema may flare because of bacterial infection, but evidence supporting antibiotic treatment is of low quality. We aimed to determine the effect of oral and topical antibiotics in addition to topical emollient and corticosteroids in children with clinically infected eczema.
\end{abstract}

METHODS We employed a 3-arm, blinded, randomized controlled trial in UK ambulatory care. Children with clinical, non-severely infected eczema were randomized to receive oral and topical placebos (control), oral antibiotic (flucloxacillin) and topical placebo, or topical antibiotic (fusidic acid) and oral placebo, for 1 week. We compared Patient Oriented Eczema Measure (POEM) scores at 2 weeks using analysis of covariance (ANCOVA).

RESULTS We randomized 113 children (40 to control, 36 to oral antibiotic, and 37 to topical antibiotic). Mean (SD) baseline Patient Oriented Eczema Measure scores were 13.4 (5.1) for the control group, 14.6 (5.3) for the oral antibiotic group, and 16.9 (5.5) for the topical antibiotic group. At baseline, 104 children (93\%) had 1 or more of the following findings: weeping, crusting, pustules, or painful skin. Mean (SD) POEM scores at 2 weeks were 6.2 (6.0) for control, 8.3 (7.3) for the oral antibiotic group, and 9.3 (6.2) for the topical antibiotic group. Controlling for baseline POEM score, neither oral nor topical antibiotics produced a significant difference in mean (95\% Cl) POEM scores (1.5 [-1.4 to 4.4] and 1.5 [-1.6 to 4.5$]$ respectively). There were no significant differences in adverse effects and no serious adverse events.

CONCLUSIONS We found rapid resolution in response to topical steroid and emollient treatment and ruled out a clinically meaningful benefit from the addition of either oral or topical antibiotics. Children seen in ambulatory care with mild clinically infected eczema do not need treatment with antibiotics.

Ann Fam Med 2017;15:124-130. https://doi.org/10.1370/afm.2038.

\section{INTRODUCTION}

E czema affects nearly 1 in 5 people in the United States and the United Kingdom and can significantly impair quality of life..$^{1-3}$ The condition is characterized by exacerbations and remissions, and in the United Kingdom it is estimated that children experience approximately 2.2 million eczema flares (worsening of their eczema) a year. ${ }^{4}$ The cause of flares, however, remains uncertain. ${ }^{5}$ There are no published data on how eczema flares are managed in primary care, but it has been estimated that $40 \%$ are treated with topical antibiotics, and our unpublished pilot study suggests that $54 \%$ of children with eczema aged 5 years or younger are given antibiotics in the course of a year. ${ }^{4}$ Widespread use of antimicrobials is a key contributor to the development of antimicrobial resistance and exposes children to possible harms from adverse effects. ${ }^{6}$

Stapbylococcus aureus (S. aureus) can be isolated from lesional skin in about $70 \%$ of patients with eczema. The odds of colonization are nearly 20 times those in people without eczema, ${ }^{7}$ and more severe eczema is associated 
with higher organism density. ${ }^{8}$ Despite the clear association between eczema and the presence of $S$. aureus, however, there is uncertainty about what constitutes infection and when antibiotic treatments are likely to confer benefit. ${ }^{9}$ A 2010 update of a Cochrane review of antimicrobial interventions for eczema found that most relevant studies were small and of poor quality. None found meaningful clinical benefit from antimicrobial intervention despite reduction in the presence of $S$. aureus, and the authors questioned the ongoing use of antibiotics for eczema flares. ${ }^{10}$

We set out to assess whether oral or topical antibiotics, in addition to standard treatment with topical corticosteroids, were more effective than placebo in reducing subjective eczema severity in children with clinically infected eczema.

\section{METHODS}

CREAM (Children with Eczema Antibiotic Management study) was a 3-arm, double-dummy, blinded, individually randomized controlled trial in ambulatory care in the United Kingdom.

\section{Participants}

Children aged 3 months to 7 years were eligible if they were consulting in a participating National Health Service (NHS) general practice or direct-access dermatology clinic for clinically infected eczema. ${ }^{11}$ Treating clinicians were asked to include patients whom they believed to have infected eczema and were given guidance that symptoms or signs suggestive of infection could include the following:

- eczema that is failing to respond to standard treatment with emollients and/or mild-to-moderate topical corticosteroids

- a flare in the severity or extent of the eczema

- weeping or crusting

Children were excluded if they had recently used potent or very potent topical corticosteroids or antibiotics or if they had features of severe infection or significant comorbid illness (Supplemental Appendix 1, available at http://www.AnnFamMed.org/ content/15/2/124/suppl/DC1/).

\section{Interventions}

Participants were randomized to 1 of 3 study arms: oral and topical placebos (the control group); oral antibiotic and topical placebo (the oral antibiotic group, or $\mathrm{OA})_{i}$ or topical antibiotic and oral placebo (the topical antibiotic group, or TA). Random allocation was undertaken by site pharmacies using block randomization with randomly chosen balanced block sizes of 6 or 9. Participants, parents, and all other members of the study team were blinded to allocation. The oral antibiotics under evaluation were flucloxacillin (floxacillin) suspension $(250 \mathrm{mg} / 5 \mathrm{~mL})$ or erythromycin suspension $(250 \mathrm{mg} / 5 \mathrm{~mL})$ for those with penicillin allergy. Parents were instructed to administer $2.5 \mathrm{~mL}$ (125mg) 4 times a day to participants aged 2 years or less and $5 \mathrm{~mL}$ (250mg) 4 times a day to older participants for 7 days. The topical antibiotic under evaluation was $2 \%$ fusidic acid cream, applied 3 times a day for 7 days. All placebos were matched according to taste and appearance. All participants were also prescribed a topical corticosteroid: hydrocortisone $1 \%$ for the face and clobetasone butyrate $0.05 \%$ (or equivalent) for other parts of the body, and an emollient of their choice (excluding emollients containing antimicrobials).

\section{Data Collection}

Research nurses conducted a baseline visit as soon as possible and no later than 72 hours after a patient was identified by a participating site. The baseline visit was used to obtain consent, collect baseline data, and supply study medication. Baseline data collected included demographics, duration of current flare, medication, symptoms, temperature, signs of infection, and the outcome measures detailed below. Parents were asked to complete a 4 -week daily diary of symptom severity (skin redness, cracking, soreness, itch, sleep disturbance, oozing or weeping, bleeding, and fever), adverse effects (nausea, vomiting, diarrhea, abdominal pain, joint pains, and new rash), medication use, and consultations. Research nurses visited participants again at 2 and 4 weeks and reviewed their medical records at 3 months. At that point, parents of participants were also asked to complete a postal questionnaire.

The primary outcome was the Patient Oriented Eczema Measure (POEM) score at 2 weeks. POEM measures subjective eczema severity over the previous week and results in a score from 0 to 72 , with higher scores representing more severe eczema severity. ${ }^{12}$ The minimum clinically important difference for POEM is about 3.13,14 Secondary outcomes were the Eczema Area and Severity Index (EASI), ${ }^{15}$ Infants Dermatitis Quality of Life instrument (IDQoL) ${ }^{16}$ for participants aged 3 months to 4 years, Children's Dermatology Life Quality Index (CDLQI) ${ }^{17}$ for participants aged 4 years to 8 years, Dermatitis Family Impact $(\mathrm{DFI})^{18}$ instrument, and the Atopic Dermatitis Quality of Life (ADQoL) instrument. ${ }^{19}$ The weight of unused study medication (including steroids) was measured at 2 weeks. The research nurses collected swabs of the eczematous skin, throat and anterior nares at baseline and week 2, and the parents were asked to do so again at 3 months. Baseline skin swabs were used to describe the prevalence of $S$. aureus found on participants' eczematous skin, and baseline 
and follow-up swabs were used to identify antimicrobial resistance in $S$. aureus and beta-hemolytic streptococci (Supplemental Appendix 2, available at http://www. AnnFamMed.org/content/15/2/124/supp1/DC1/).

\section{Analysis}

Our initial sample size calculation was based on a clinically important difference of 3 in POEM score and a common standard deviation of 7. Using $\alpha=0.025$ and $90 \%$ power we determined that we required 137 participants per treatment group, giving a total of 411 , or 517 when allowing $20 \%$ loss to follow-up. In April 2014, we used the data from the first 69 participants to revisit some of the parameters in the sample size calculation. Using the standard deviation from the baseline POEM scores (5.3) and the correlation between baseline and 2-week POEM scores (0.27) and the same clinically important difference for POEM, we found that 75 patients per group are required to reach $90 \%$ power, giving a total of 225 required for analysis. Continuing to allow 20\% loss to follow-up resulted in a revised recruitment target of 282 participants.

Our primary analyses were intention-to-treat comparisons of week 2 POEM scores in each of the 2 intervention groups with control, adjusted for baseline POEM scores using ANCOVA. Secondary analyses were also carried out using ANCOVA. We used rules on missing data from the score questionnaire developers (Supplemental Appendix 3, available at http://www. AnnFamMed.org/content/15/2/124/suppl/DC1/). Daily symptom scores were added to create a total daily symptom severity score. Mean daily symptom scores for each group were plotted and compared using areaunder-the-curve analyses. Medication use was calculated as the proportion between the number of doses/ applications recorded in the patient diary and the total number of prescribed doses for that medication. Topical corticosteroids were classified as mild, moderate, potent, or very potent using British National Formulary classification. ${ }^{20}$ Skin swab results were expressed as the proportion of participants in whom $S$. aureus was isolated at each time point and the proportion of these swabs with resistance to medications under investigation.

We converted data on adverse effects to a binary variable using slight problem or worse as a cut-point, and we compared the odds of experiencing any adverse effect in each of the treatment groups with those in the control group.

We also conducted sensitivity analyses to assess for efficacy while controlling for adherence (Complier Average Casual Effect [CACE]) and to assess potential information bias from missing data (multiple imputation). A CACE analysis aims to estimate the causal effects of the intervention in those individuals who comply with (adhere to) treatment, and is recommended over per-protocol analyses. ${ }^{21}$

Analyses were conducted using SPSS version 20 (IBM Corp). The full trial protocol is available as a supplementary file (Supplemental Appendix 4, available at http://www.AnnFamMed.org/content/15/2/124/ suppl/DC1/). The study was approved by the National Research Ethics Service South Wales Ethics Committee (Reference: 12/WA/0180), and is registered with the ISRCTN registry: 96705420.

\section{RESULTS}

Ninety-four sites (90 general practices and 4 hospital dermatology clinics) were opened between July 2013 and November 2014, and of these, 33 (32 general practices and 1 dermatology clinic) recruited 1 or more participants. Participating sites were slightly larger than non-participating practices (mean practice list size 9,452 vs 6,451 ), but there were no significant differences in number of partners, proportion of list aged 8 years or less, or proportion of children aged 8 years or less who have eczema. ${ }^{22}$

One hundred thirteen participants were randomized (Supplemental Appendix 5, available at http://www. AnnFamMed.org/content/15/2/124/supp1/DC1/), which was less than the target sample size. Three participants had penicillin allergy, but none were randomized to the oral antibiotics group, so no participants received oral erythromycin. There were no significant differences in baseline characteristics among the 3 groups (Table 1). More than $90 \%$ of participants had 1 or more classic signs of infection recorded by the recruiting clinician, and $70 \%$ had S. aureus isolated from a skin swab. Nurse baseline assessments $(\mathrm{n}=100)$ revealed that $30.0 \%$, $10.1 \%, 6.8 \%$, and $53.0 \%$ had moderate or severe crusting, weeping, pustules, and erythema respectively.

POEM scores were similar in the 3 groups at baseline, and reduced (improved) in all 3 groups by 2 weeks (Table 2). At 2 weeks there were no significant differences between POEM scores in the 2 intervention groups compared with control, controlling for baseline POEM score (Table 2).

POEM scores at 4 weeks and 3 months, and other secondary outcomes, all suggested no or minimal clinical benefit from oral or topical antibiotics (Table 2 and Supplemental Appendix 6, available at http:// www.AnnFamMed.org/content/15/2/124/suppl/DC1/). Total daily symptom scores decreased over the first week and then stayed relatively stable (Supplemental Appendix 7, available at http://www. AnnFamMed. org/content/15/2/124/suppl/DC1/), and there were no significant differences in symptom scores between the 3 groups. There were no significant differences 
Table 1. Baseline Characteristics

\begin{tabular}{|c|c|c|c|c|}
\hline & $\begin{array}{l}\text { Control } \\
(n=40)\end{array}$ & $\begin{array}{c}\text { Oral } \\
\text { Antibiotic } \\
(\mathrm{n}=36)\end{array}$ & $\begin{array}{c}\text { Topical } \\
\text { Antibiotic } \\
(\mathrm{n}=37)\end{array}$ & $\begin{array}{c}\text { Overall } \\
(n=113)\end{array}$ \\
\hline Age, mean (SD) & $3.3(2.2)$ & $2.9(2.2)$ & $3.0(2.1)$ & $3.1(2.1)$ \\
\hline \multicolumn{5}{|l|}{ Gender, n (\%) } \\
\hline Male & $17(42.5)$ & $18(50.0)$ & $17(45.9)$ & $52(46.0)$ \\
\hline Female & $23(57.5)$ & $18(50.0)$ & $20(54.1)$ & $61(54.0)$ \\
\hline \multicolumn{5}{|l|}{ Ethnicity, n (\%) } \\
\hline White & $33(82.5)$ & $31(86.1)$ & $27(73.0)$ & $91(80.5)$ \\
\hline Mixed & $4(10.0)$ & $1(2.8)$ & $3(8.1)$ & $8(7.1)$ \\
\hline Asian, Chinese or other & $1(2.5)$ & $3(8.3)$ & $3(8.1)$ & $7(6.2)$ \\
\hline Black & $2(5.0)$ & $0(0.0)$ & $3(8.1)$ & $5(4.4)$ \\
\hline Prefer not to answer & $0(0.0)$ & $1(2.8)$ & $1(2.7)$ & $2(1.8)$ \\
\hline \multicolumn{5}{|l|}{ Duration of eczema flare, ${ }^{a} \mathrm{n}(\%)$} \\
\hline $1-3$ days & $3(12.5)$ & $3(13.0)$ & $2(10.0)$ & 8 (11.9) \\
\hline 4-7 days & $10(41.7)$ & $9(39.1)$ & $4(20.0)$ & $23(34.3)$ \\
\hline 8-14 days & 7 (29.2) & $7(30.4)$ & $5(25.0)$ & $19(28.4)$ \\
\hline 15-28 days & $4(16.7)$ & $4(17.4)$ & $9(45.0)$ & $17(25.4)$ \\
\hline \multicolumn{5}{|l|}{ Clinical features, ${ }^{\mathrm{b}} \mathrm{n}(\%)$} \\
\hline Itchy skin & $37(94.9)$ & $35(97.2)$ & $35(94.6)$ & $107(95.5)$ \\
\hline Dry skin & $37(94.9)$ & $35(97.2)$ & $37(100)$ & $109(97.3)$ \\
\hline Weeping or oozing skin lesion & $19(48.7)$ & $20(55.6)$ & $22(59.5)$ & $61(54.5)$ \\
\hline Crusting & $27(69.2)$ & $28(77.8)$ & $28(75.7)$ & $83(74.1)$ \\
\hline Pustules & $13(33.3)$ & $14(38.9)$ & 7 (18.9) & $34(30.4)$ \\
\hline Fever during this illness & $7(18.0)$ & $10(27.8)$ & $6(16.2)$ & $23(20.5)$ \\
\hline Painful skin & $23(59.0)$ & $25(69.4)$ & $31(83.8)$ & 79 (70.5) \\
\hline Hypersensitivity of skin & $26(66.7)$ & $27(75.0)$ & $27(73.0)$ & $80(71.4)$ \\
\hline Disturbed sleep & $26(66.7)$ & $28(77.8)$ & $25(67.6)$ & 79 (70.5) \\
\hline Feeling generally unwell & $11(28.2)$ & $15(41.7)$ & $13(35.1)$ & 39 (34.8) \\
\hline Interference in normal activities & $9(23.1)$ & $19(52.8)$ & $18(48.7)$ & $46(41.1)$ \\
\hline \multicolumn{5}{|l|}{ Features of infection, n (\%) } \\
\hline $\begin{array}{l}\text { One or more of weeping, crusting, } \\
\text { pustules, fever, or painful skin }\end{array}$ & $36(92.3)$ & $33(91.7)$ & $35(94.6)$ & $104(92.9)$ \\
\hline Growth of S. aureus from skin swab & $16(60.0)$ & $30(83.3)$ & $24(66.7)$ & $78(69.6)$ \\
\hline \multicolumn{5}{|l|}{$\begin{array}{l}\text { Prescribed topical corticosteroids, } \\
\text { n (\%) }\end{array}$} \\
\hline Mild only & $19(48.7)$ & $16(45.7)$ & $12(32.4)$ & $47(42.3)$ \\
\hline Moderate only & $15(38.5)$ & $15(42.9)$ & $16(43.2)$ & $46(41.4)$ \\
\hline Both mild \& moderate & $5(12.8)$ & $4(11.4)$ & $9(24.3)$ & $18(16.2)$ \\
\hline
\end{tabular}

biotic group. By 3 months, nonsusceptibility rates had reverted to $15 \%$ overall and $25 \%$ in the topical antibiotic group (Supplemental Appendix 9, available at http://www.AnnFamMed.org/ content/15/2/124/suppl/DC1/).

No serious adverse events were reported. New rash, diarrhea, and vomiting were the most common adverse events reported, experienced by $17.5 \%, 15.5 \%$, and $12.4 \%$ of participants respectively. There were no notable differences by treatment group (Supplemental Appendix 10, available at http://www.AnnFamMed.org/ content/15/2/124/suppl/DC1/).

\section{DISCUSSION}

In this study, children with clinically infected eczema flares in primary care recovered quickly with use of mild-to-moderatestrength topical corticosteroids and did not benefit from the addition of either oral or topical antibiotics. The study did not meet its recruitment target, but the lower bands of the confidence intervals for treatment effects $(-1.4$ and -1.6$)$ are less than the published minimal clinically important difference for POEM, suggesting that these results are not due to chance and that the conclusion that antibiotics offered no meaningful benefit would have been unlikely to change even if the sample size

in reported use of topical corticosteroids (Table 3). Adjusting for medication use or missing data did not affect the results (Supplemental Appendix 8, available at http://www.AnnFamMed.org/content/15/2/124/ suppl/DC1/).

Seventy percent of patients had S. aureus cultured from eczematous skin at baseline; the percentage decreased to $44 \%$ and $36 \%$ at 2 weeks and 3 months respectively, with no significant differences between groups. Twenty-seven percent of baseline isolates were resistant to fusidic acid, and at 2 weeks this increased to $31 \%$ overall and $73 \%$ in the topical anti- had been achieved. ${ }^{13,14}$ Secondary analyses were all consistent and in the same direction, showing small effect sizes and confidence intervals that included zero.

\section{Strengths and Limitations}

We have conducted the largest trial to evaluate the effect of oral and topical antibiotic treatment for clinically infected eczema in children and the only such trial to be conducted in ambulatory care, where most children with eczema flares are treated. Randomization was conducted independently, we used matched placebos, and there were no breaches in allocation 
Table 2. Effect of Oral and Topical Antibiotics on Subjective and Objective Eczema Severity at 2 Weeks, 4 Weeks, and 3 Months

\begin{tabular}{|c|c|c|c|c|c|c|c|}
\hline \multirow[b]{2}{*}{ Outcome } & \multicolumn{3}{|c|}{ Control } & \multicolumn{4}{|c|}{ Oral Antibiotic } \\
\hline & $\mathbf{N}$ & $\begin{array}{l}\text { Baseline, Mean } \\
\text { (SD) }\end{array}$ & $\begin{array}{l}\text { Follow-up, Mean } \\
\text { (SD) }\end{array}$ & $\mathbf{N}$ & $\begin{array}{l}\text { Baseline, Mean } \\
\text { (SD) }\end{array}$ & $\begin{array}{l}\text { Follow-up, Mean } \\
\text { (SD) }\end{array}$ & $\begin{array}{c}\text { Intervention Effect } \\
(95 \% \mathrm{Cl})\end{array}$ \\
\hline \multicolumn{8}{|l|}{ POEM } \\
\hline 2 weeks $^{a}$ & 36 & $13.4(5.1)$ & $6.2(6.0)$ & 34 & $14.6(5.3)$ & $8.3(7.3)$ & $1.5(-1.4,4.4)$ \\
\hline 4 weeks & 35 & $13.6(5.0)$ & $8.0(6.0)$ & 33 & $14.6(5.4)$ & $8.4(7.7)$ & $-0.2(-3.1,2.8)$ \\
\hline 3 months & 25 & $13.7(5.1)$ & $7.7(5.5)$ & 28 & $14.4(5.7)$ & $7.8(6.1)$ & $-0.2(-3.1,2.7)$ \\
\hline \multicolumn{8}{|l|}{ EASI } \\
\hline 2 weeks & 34 & $5.8(5.0)$ & $2.5(5.6)$ & 34 & $7.3(6.1)$ & $3.1(3.6)$ & $0.2(-0.1,0.5)$ \\
\hline 4 weeks & 34 & $5.8(5.0)$ & $4.0(6.6)$ & 33 & $7.4(6.2)$ & $3.2(3.8)$ & $-0.1(-0.5,0.2)$ \\
\hline
\end{tabular}

$\mathrm{EASI}=\mathrm{Eczema}$ Area and Severity Index (objective eczema severity); POEM = Patient Oriented Eczema Measure (subjective eczema severity).

Primary outcome.

Table 3. Use of Topical Corticosteroids by Treatment Group

\begin{tabular}{|c|c|c|c|c|c|c|}
\hline & \multicolumn{2}{|c|}{$\begin{array}{l}\text { Control } \\
n=36\end{array}$} & \multicolumn{2}{|c|}{$\begin{array}{l}\text { Oral Antibiotic } \\
\qquad n=34\end{array}$} & \multicolumn{2}{|c|}{$\begin{array}{c}\text { Topical Antibiotic } \\
n=30\end{array}$} \\
\hline & $n^{a}(\%)$ & $\begin{array}{c}\text { Applicationsl } \\
\text { wk, Mean (SD) }\end{array}$ & $n^{a}(\%)$ & $\begin{array}{c}\text { Applicationsl } \\
\text { wk, Mean (SD) }\end{array}$ & $n^{a}(\%)$ & $\begin{array}{c}\text { Applicationsl } \\
\text { wk, Mean (SD) }\end{array}$ \\
\hline Mild & $19(52.8)$ & $8.4(6.6)$ & $21(61.8)$ & $7.0(4.8)$ & $15(50.0)$ & $7.1(4.5)$ \\
\hline Moderate & $24(66.7)$ & $7.0(4.1)$ & $22(64.7)$ & $6.9(2.8)$ & $24(80.0)$ & $7.3(3.9)$ \\
\hline
\end{tabular}

concealment. We found no evidence of differential use of medications, including topical corticosteroids, and adjusting for compliance did not alter our findings. Blinded outcome assessors used well-validated instruments to assess subjective and objective eczema severity at baseline and at follow-up. We achieved high rates of follow-up, and our primary analysis was by intention to treat. Analysis of longer-term follow-up and analyses controlling for missing data were all consistent with our main finding that neither topical nor oral antibiotics offer any clinically important benefit.

There is no standard definition of infected eczema, so we used pragmatic inclusion criteria based on clinical suspicion of infection. Included children were clearly experiencing flares in their eczema, considering that their mean baseline POEM scores were higher than those found in other ambulatory care studies $\left(8.9\right.$ and 9.8 in $\mathrm{COMET}^{23}$ and $\mathrm{BATHE}^{24}$ studies respectively; unpublished data), there was a significant improvement in severity scores during the follow-up period in all groups, more than $90 \%$ had 1 or more "classical" signs of infection, and $70 \%$ had S. aureus isolated from baseline swabs. Fewer than one-third, however, had moderate to severe crusting, and only 1 in 10 had moderate to severe weeping, so it is possible that not all participants had actual infection. Nevertheless, all patients had what clinicians believed to be infected eczema, so the evidence provided by this study is of direct relevance to current practice. The mean age of children in our study was less than 3 years, and only a small number of participants were from ethnic minorities. Therefore, our results may not be generalizable to older children or those from ethnic minorities.

\section{Comparison With Other Studies}

The only previous study to assess the effect of an antibiotic in children with clinically infected eczema involved only 33 children and found no difference between those randomized to cefadroxil and those randomized to placebo. ${ }^{25}$ Two further studies have examined the effects of topical antibiotics in children and adults with clinically infected eczema. Both studies reported improvements in investigator-graded severity over time, and both reported significantly better follow-up scores in those treated with combined antibiotic/steroid compared with each component individually or control. ${ }^{26,27}$ Neither study, however, used any patient-reported or validated outcome measures, and neither study analyzed children separately. Two small trials of oral antibiotics failed to demonstrate any beneficial effect in children and adults with clinically uninfected eczema, ${ }^{28,29}$ and a trial of topical mupirocin plus hydrocortisone in 83 infants found no benefit over steroid alone in terms of the primary outcome but did 
Topical Antibiotic

\section{N}

Baseline, Mean (SD)

Follow-up, Mean

\begin{tabular}{llll}
31 & $16.9(5.5)$ & $9.3(6.2)$ & $1.5(-1.6,4.5)$ \\
30 & $16.6(5.4)$ & $9.5(5.9)$ & $0.0(-3.1,3.1)$ \\
21 & $16.4(5.5)$ & $7.9(5.6)$ & $-1.1(-4.3,2.1)$ \\
& & & \\
31 & $9.5(9.7)$ & $4.9(5.6)$ & $0.4(0.1,0.8)$ \\
30 & $9.7(9.8)$ & $5.0(6.9)$ & $0.0(-0.3,0.4)$ \\
\hline
\end{tabular}

report a significant lower EASI score in the combination group at day $8 .^{30}$

\section{Implications for Practice and Research}

Our data provide strong evidence that not all children with clinically infected eczema need to be treated with antibiotics. We recruited only a small proportion of potentially eligible study subjects, however, and excluded patients with severe infection. The table of baseline characteristics suggests that our cohort tended to have relatively mild signs of infection, so our results may not be generalizable to all children with clinically infected eczema. A greater understanding of different eczema infective flare phenotypes would help better define the boundary between those who clearly do not benefit from antibiotics and those who might. Some patients in this study may not have had infection at all. Without greater clarity about what constitutes infection in this context, however, it is difficult for clinicians to define infection clearly. Further research to better define clinically infected eczema may be helpful, but it is clear that at least some patients currently defined as having infected eczema are not benefiting from antimicrobial therapy. Topical antibiotics are frequently used in ambulatory care, especially in combination products with topical corticosteroids, and their use can promote resistance and allergy or skin sensitization. ${ }^{31-33}$ We found resistance to fusidic acid in more than a quarter of patients at baseline and nearly three-quarters of the group treated with fusidic acid at follow-up. Less than $1 \%$ of $S$. aureus from community samples is methicillin resistant, and the lack of benefit in the flucloxacillin group, despite low levels of resistance to flucloxacillin found in our baseline swabs, suggests that resistance is unlikely to account for the lack of effect observed in this study. ${ }^{34}$

Children in all 3 treatment groups experienced substantial improvement in eczema severity over the first week following randomization. Little has been published about the natural history of eczema flares, so our finding that symptomatic improvement occurs over the first week and then levels off provides what is probably the best available evidence about recovery from clinically infected eczema flares that are treated with topical corticosteroids and emollients. The use of topical corticosteroids for eczema flares has a substantial evidence base, and participants recovered well with use of topical corticosteroids and emollients, so providing (or stepping up the potency of) topical corticosteroids and emollients should be the main focus in the care of milder clinically infected eczema flares. ${ }^{35}$

To read or post commentaries in response to this article, see it online at http://www.annfammed.org/content/15/2/124.

Key words: eczema; infection; anti-bacterial agents.

Submitted July 13, 2016; submitted, revised, October 26, 2016; accepted November 20, 2016.

Funding support: This project was funded by the National Institute for Health Research Health Technology Assessment Programme (project number 09/118/03).

Previous presentations: General Practice Research on Infections Network (GRIN); October 2-3, 2015; Galway, Ireland; South West Society for Academic Primary Care; March 1-2, 2016; Cardiff, Wales; and the International Symposium on Atopic Dermatitis; May 19-21, 2016; São Paulo, Brazil.

Acknowledgments: We are very grateful to the parents and children who participated in the study and to the general practice and dermatology unit staff who acted as recruiting sites. We also thank Inaam Haq and Eleri Owen-Jones, trial managers, and Katy Addison and Natasha Kalebic, data managers. We would also like to acknowledge Robin Howe, Amanda Roberts, Mark Kelson, Miguel Cosio and Peter Davey, who contributed to the trial development and management. We would like to thank all members of the local research teams in Wales, Dundee and Bristol, including Nicki Mitchell, Anna Gilbertson, Becki Elliot-Jones, Lyn Liddiard, Julia Carver, and the National Institute for Social Care and Health Research (now Health and Care Research Wales) primary care workforce. We would like to thank Jennifer Richards and Leanne Davies (SACU Laboratory, Cardiff) who contributed to the acquisition of microbiology data. We are most grateful to our Trial Steering Committee (Anthony Harnden, Kim Thomas, and Gladys Hingco) and our Data Monitoring Committee (Sonia Saxena, Miriam Santer, and Mark Mullee). We are very grateful to the National Institute for Health Research Health Technology Assessment Programme, who funded the research.

- Supplementary materials: Available at http://www.AnnFamMed. org/content/15/2/124/suppl/DC1/.

\section{References}

1. Hanifin JM, Reed ML; Eczema Prevalence and Impact Working Group. A population-based survey of eczema prevalence in the United States. Dermatitis. 2007;18(2):82-91.

2. Emerson RM, Williams HC, Allen BR. What is the cost of atopic dermatitis in preschool children? Br J Dermatol. 2001;144(3):514-522. 
3. Beattie PE, Lewis-Jones MS. A comparative study of impairment of quality of life in children with skin disease and children with other chronic childhood diseases. Br J Dermatol. 2006;155(1):145-151.

4. NHS National Institute for Health Clinical Excellence (NICE). National Costing Report: Atopic Eczema in Children. London, England: NICE; 2008.

5. Langan SM, Schmitt J, Williams HC, Smith S, Thomas KS. How are eczema 'flares' defined? A systematic review and recommendation for future studies. Br J Dermatol. 2014;170(3):548-556.

6. Aagaard L, Hansen EH. Adverse drug reactions reported for systemic antibacterials in Danish children over a decade. Br J Clin Pharmacol. 2010;70(5):765-768.

7. Totté JE, van der Feltz WT, Hennekam M, van Belkum A, van Zuuren EJ, Pasmans SG. Prevalence and odds of Staphylococcus aureus carriage in atopic dermatitis: a systematic review and metaanalysis. Br J Dermatol. 2016;175(4):687-695.

8. Higaki S, Morohashi M, Yamagishi T, Hasegawa Y. Comparative study of staphylococci from the skin of atopic dermatitis patients and from healthy subjects. Int J Dermatol. 1999;38(4):265-269.

9. Birnie AJ, Bath-Hextall FJ, Ravenscroft JC, Williams HC. Interventions to reduce Staphylococcus aureus in the management of atopic eczema. Cochrane Database Syst Rev. 2008;(3):CD003871.

10. Bath-Hextall FJ, Birnie AJ, Ravenscroft JC, Williams HC. Interventions to reduce Staphylococcus aureus in the management of atopic eczema: an updated Cochrane review. Br J Dermatol. 2010;163(1): $12-26$.

11. Williams HC, Burney PG, Hay RJ, et al. The U.K. Working Party's Diagnostic Criteria for Atopic Dermatitis. I. Derivation of a minimum set of discriminators for atopic dermatitis. Br J Dermatol. 1994; 131(3):383-396.

12. Charman CR, Venn AJ, Williams HC. The patient-oriented eczema measure: development and initial validation of a new tool for measuring atopic eczema severity from the patients' perspective. Arch Dermatol. 2004;140(12):1513-1519.

13. Schram ME, Spuls PI, Leeflang MMG, Lindeboom R, Bos JD, Schmitt J. EASI, (objective) SCORAD and POEM for atopic eczema: responsiveness and minimal clinically important difference. Allergy. 2012;67(1):99-106.

14. Gaunt DM, Metcalfe C, Ridd M. The Patient-Oriented Eczema Measure in young children: responsiveness and minimal clinically important difference. Allergy. 2016;71(11):1620-1625.

15. Hanifin JM, Thurston M, Omoto M, Cherill R, Tofte SJ, Graeber M; EASI Evaluator Group. The eczema area and severity index (EASI): assessment of reliability in atopic dermatitis. Exp Dermatol. 2001; 10(1):11-18.

16. Lewis-Jones MS, Finlay AY, Dykes PJ. The Infants' Dermatitis Quality of Life Index. Br J Dermatol. 2001;144(1):104-110.

17. Lewis-Jones MS, Finlay AY. The Children's Dermatology Life Quality Index (CDLQI): initial validation and practical use. $\mathrm{Br} J$ Dermatol. 1995;132(6):942-949.

18. Lawson V, Lewis-Jones MS, Finlay AY, Reid P, Owens RG. The family impact of childhood atopic dermatitis: the Dermatitis Family Impact Questionnaire. Br J Dermatol. 1998;138(1):107-13.

19. Stevens KJ, Brazier JE, McKenna SP, Doward LC, Cork MJ. The development of a preference-based measure of health in children with atopic dermatitis. Br J Dermatol. 2005;153(2):372-377.
20. Joint Formulary Committee. British National Formulary (BNF) 69. London, England: Pharmaceutical Press; 2015.

21. Keogh-Brown MR, Bachmann MO, Shepstone L, et al. Contamination in trials of educational interventions. Health Technol Assess. 2007;11(43):iii-ix-107,ix-107.

22. Francis NA, Ridd MJ, Thomas-Jones E, et al.; CREAM team. A randomised placebo-controlled trial of oral and topical antibiotics for children with clinically infected eczema in the community: the ChildRen with Eczema, Antibiotic Management (CREAM) study. Health Technol Assess. 2016;20(19):i-xxiv,1-84.

23. Ridd MJ, Garfield K, Gaunt DM, et al. Choice of Moisturiser for Eczema Treatment (COMET): feasibility study of a randomised controlled parallel group trial in children recruited from primary care. BMJ Open. 2016 Nov 16;6(11):e012021.

24. Santer M, Rumsby K, Ridd MJ, et al. Bath additives for the treatment of childhood eczema (BATHE): protocol for multicentre parallel group randomized trial. BMJ Open. 2015 Nov 1;5(10):e009575.

25. Weinberg $E$, Fourie B, Allmann B, Toerien A. The use of cefadroxil in superinfected atopic dermatitis. Curr Thera Res. 1992;52(5):671-676.

26. Wachs GN, Maibach HI. Co-operative double-blind trial of an antibiotic/corticoid combination in impetiginized atopic dermatitis. $\mathrm{Br}$ J Dermatol. 1976;95(3):323-328.

27. Larsen FS, Simonsen L, Melgaard A, Wendicke K, Henriksen AS. An efficient new formulation of fusidic acid and betamethasone 17-valerate (fucicort lipid cream) for treatment of clinically infected atopic dermatitis. Acta Derm Venereol. 2007;87(1):62-68. 10.2340/00015555-0174.

28. Ewing $\mathrm{Cl}$, Ashcroft C, Gibbs AC, Jones GA, Connor PJ, David TJ. Flucloxacillin in the treatment of atopic dermatitis. Br J Dermatol. 1998; 138(6):1022-1029.

29. Boguniewicz M, Sampson H, Leung SB, Harbeck R, Leung DY. Effects of cefuroxime axetil on Staphylococcus aureus colonization and superantigen production in atopic dermatitis. J Allergy Clin Immunol. 2001; 108(4):651-652.

30. Canpolat F, Erkoçoğlu M, Tezer H, Kocabaş CN, Kandi B. Hydrocortisone acetate alone or combined with mupirocin for atopic dermatitis in infants under two years of age - a randomized double blind pilot trial. Eur Rev Med Pharmacol Sci. 2012;16(14):1989-1993.

31. Ravenscroft JC, Layton A, Barnham M. Observations on high levels of fusidic acid resistant Staphylococcus aureus in Harrogate, North Yorkshire, UK. Clin Exp Dermatol. 2000;25(4):327-330.

32. Hon KL, Wang SS, Lee KKC, Lee VWY, Leung TF, Ip M. Combined antibiotic/corticosteroid cream in the empirical treatment of moderate to severe eczema: friend or foe? J Drugs Dermatol. 2012;11(7):861-864.

33. Heng YK, Tan KT, Sen P, et al. Staphylococcus aureus and topical fusidic acid use: results of a clinical audit on antimicrobial resistance. Int J Dermatol. 2013;52(7):876-881.

34. Maudsley J, Stone SP, Kibbler CC, et al. The community prevalence of methicillin-resistant Staphylococcus aureus (MRSA) in older people living in their own homes: implications for treatment, screening and surveillance in the UK. J Hosp Infect. 2004;57(3):258-262.

35. Nilsson EJ, Henning CG, Magnusson J. Topical corticosteroids and Staphylococcus aureus in atopic dermatitis. J Am Acad Dermatol. 1992;27(1):29-34. 